Case Report

\title{
Recurrent meningitis: an enigma: A Case Report
}

\author{
A Lois ${ }^{1}, \mathrm{~S} \mathrm{Save}^{1}, \mathrm{~N}$ Narkhede ${ }^{1}, \mathrm{~A} \mathrm{De}^{2}, \mathrm{~N} \mathrm{Chatterji}^{2}, \mathrm{~J} \mathrm{Shastri}^{2}$ \\ Sri Lankan Journal of Infectious Diseases 2021 Vol.11(2):133-138 \\ DOI: http://dx.doi.org/10.4038/sljid.v11i2.8362
}

\begin{abstract}
Salmonella meningitis in children represents $13 \%$ of meningitis cases in developing countries. A case of recurrent Salmonella ser. Enteritidis meningitis in a 2.5 month old baby should alert the clinician for possibility of recurrence after successful antibiotic therapy and need to investigate for the possibility of immunodeficiency.
\end{abstract}

Keywords: infant, immunodeficiency, recurrent meningitis, Salmonella meningitis

\section{Introduction}

Salmonellosis is a global public health problem. It is an infection acquired by oral and faeco-oral routes. Risk factors for the development of gastrointestinal infection in children include contact with an infected member of the household, consumption of infant formula, visits to health centres and consumption of untreated water. ${ }^{1}$

Salmonella meningitis accounts for a very small proportion of all cases of bacterial meningitis and the incidence worldwide is less than $1 \%$ and 13\% in developed and developing countries respectively. ${ }^{2,3}$ Salmonellae are facultative intracellular micro-organisms, and inadequate drug penetration may result in infection progression. ${ }^{4}$ Salmonella meningitis should therefore be treated with a third-generation cephalosporin with an adequate duration of at least three weeks. ${ }^{5}$ A very few cases of meningitis caused by $S$. Enteritidis have been reported in India and worldwide. We report a rare case of recurrent meningitis caused by $S$. Enteritidis in a two and half month old child with immunodeficiency.

${ }^{1}$ Department of Paediatrics, Topiwala National Medical College, Mumbai, India

${ }^{2}$ Department of Microbiology, Topiwala National Medical College, Mumbai, India

Address for correspondence: Dr. Sushma Save, Ajmera AEON,2002, North(B)Wing, Bhakti Park, Wadala (East)

Mumbai 400037, India. Telephone: 91-9819096819 E-mail: sushmasave73@gmail.com

(iD) https://orcid.org/0000-0002-6498-7962

Received 26 April 2021 and revised version accepted 22 September 2021.

(c) (†)

use, distribution, and reproduction in any medium, provided the original author and source are credited. 


\section{Case report}

A firstborn $2 \frac{1}{2}$ month old male child of non-consanguineous marriage was admitted with moderate grade fever for two days. He had one episode of a paroxysmal event in the form of uprolling of eyeballs and frothing from angle of mouth, tightening of limbs, which lasted for about 5 minutes and subsided on its own. There was no history of vomiting, lethargy or irritability. The child was immunized only with the birth dose of BCG, OPV and hepatitis B. The child was fed with cow's milk in addition to breast milk because of the mother's perception of a low milk output. The cow's milk was pasteurized, boiled and cooled. The child was admitted at a private hospital where meningitis was suspected, and lumbar puncture done and CSF sent for routine tests and microscopy. He was then started on intravenous ceftriaxone $100 \mathrm{mg} / \mathrm{kg} / \mathrm{day}$ in two divided doses. The parents got the child discharged against medical advice due to financial constraints and got him readmitted at our hospital around four hours later.

On physical examination, the baby was active with a temperature of $39{ }^{\circ} \mathrm{C}$, heart rate 140 beats/minute (normal for age), and respiratory rate of $44 /$ minute. On general examination: Length: $62 \mathrm{~cm}$ (between median and $+1 \mathrm{SD}$ ), Weight: $5.8 \mathrm{~kg}$ (between median and +1SD), Head circumference: $41 \mathrm{~cm}$ (at median), Weight/length: between $-1 \mathrm{SD}$ and $-2 \mathrm{SD}$, the anterior fontanelle was normal, measuring $2 \mathrm{~cm} \times 2 \mathrm{~cm}$. The child had an erythematous rash over the entire back which subsided on its own in 1-2 days. Central nervous system examination revealed extensor plantar reflexes. Rest of the systemic examination was normal.

Complete haemogram showed $\mathrm{Hb}: 9.1 \mathrm{gm} / \mathrm{dL}$ (10.5-14), total leucocyte count of 13,600 cells $/ \mathrm{mm}^{3}$ (6000 - 14000), and platelets $3.1 \times 10^{6} / \mathrm{mm}^{3}(1.5-4)$. CT brain was normal. CSF analysis revealed $8 \mathrm{mg} / \mathrm{dL}$ of glucose, protein $232.4 \mathrm{mg} / \mathrm{dL}$, and white blood cells (WBC) 8990 cells $/ \mathrm{mm}^{3}$ with $82 \%$ neutrophils and $18 \%$ lymphocytes. Corresponding blood sugar was $76 \mathrm{mg} / \mathrm{dL}$. His serum potassium was $4 \mathrm{mmol} / \mathrm{L}$ (3.5-5.6), serum sodium 140mmol/L (134-144), serum calcium $9 \mathrm{mg} / \mathrm{dL}(8.8-10.8)$, serum creatinine $0.3 \mathrm{mg} / \mathrm{dL}(0.6-0.8)$ and serum urea $6 \mathrm{mg} / \mathrm{dL}$ (5-18) which were all within normal limits.

The child was started empirically on intravenous ceftriaxone $100 \mathrm{mg} / \mathrm{kg} /$ day in two divided doses, after the collection of blood sample for culture and CSF for cytological, biochemical, and microbiological evaluation. Blood and CSF culture grew Salmonella species. Blood culture was done using an automated blood culture BACTEC system, and conventional culture was used for CSF. Identification was carried out using standard biochemical tests. Slide agglutination using Salmonella polyvalent antisera and type specific antiserum confirmed the isolate to be $S$. Enteritidis. The antibiotic sensitivity of Salmonella in blood and CSF was done by modified Kirby Bauer disc diffusion method and Epsilometer strip test as applicable and instructed by CLSI 2018 guidelines. ${ }^{6}$ Table 1 shows the antibiotic sensitivity pattern.

The child responded to intravenous ceftriaxone $(100 \mathrm{mg} / \mathrm{kg} /$ day $)$ in two divided doses 12 hourly for three weeks. Though the baby's mother was asymptomatic, she was also investigated to look for a source of infection. Blood, urine, and breast milk of the mother sent for culture were negative. Stool cultures were however not done. The child was on pasteurized and boiled cow's 
milk at home, hence testing of the cow's milk with which the baby was fed at home was not done. The child was discharged upon clinical improvement.

Table 1 - Antibiotic sensitivity of Salmonella in blood and CSF

\begin{tabular}{|l|l|l|l|l|l|l|l|l|}
\hline Specimen & AIIMS identification & CIP & CTR & FIX & AMP & SXT & CHL & AZM \\
\hline Blood & S. Enteritidis & S & S & S & S & S & S & S \\
\hline CSF & S. Enteritidis & S & S & S & S & S & S & S \\
\hline
\end{tabular}

AIIMS- All India Institute of Medical Sciences, New Delhi, CIP - Ciprofloxacin, CTR - Ceftriaxone, FIX - Cefixime, AMP Ampicillin, SXT - Trimethoprim/Sulfamethoxazole, CHL - Chloramphenicol, AZM - Azithromycin]

The child was readmitted one month after discharge with fever, refusal of feeds, and irritability for two days. During this admission the child had increased tone and brisk reflexes and extensor plantars. Other systemic examinations were normal. On admission, the $\mathrm{Hb}$ was $10.2 \mathrm{gm} / \mathrm{dL}$ (normal range 10.5-14), and WBC 15,400 cells $/ \mathrm{mm}^{3}$ (normal range 6000-14000). Magnetic Resonance Imaging (MRI) of the brain was suggestive of diffuse meningitis. CSF glucose was $21 \mathrm{mg} / \mathrm{dL}$ (blood sugar $85 \mathrm{mg} / \mathrm{dL}$ ), protein $120 \mathrm{mg} / \mathrm{dL}$, and WBC 736 cells $/ \mathrm{mm}^{3}$ (neutrophils $74 \%$; lymphocytes $26 \%$ ) were suggestive of pyogenic meningitis.

He was treated with intravenous ceftriaxone $100 \mathrm{mg} / \mathrm{kg} /$ day in two divided doses, phenobarbitone $5 \mathrm{mg} / \mathrm{kg} /$ day and levetiracetam $10 \mathrm{mg} / \mathrm{kg} /$ day for the seizures which he eventually developed. Blood and CSF cultures again showed growth of Salmonella group D (S. Enteritidis), similar to the organism obtained one month previously during the first admission. He was treated with intravenous ceftriaxone $(100 \mathrm{mg} / \mathrm{kg} /$ day) in two divided doses for 28 days and intravenous ciprofloxacin $(10 \mathrm{mg} / \mathrm{kg} /$ dose 8 hourly) for 10 days along with supportive treatment. A primary immunodeficiency workup done during this admission showed decreased IgM levels. The child was discharged upon clinical improvement with proper neurodevelopmental assessment and regularly followed up for complications.

At seven months of age, the child had a discharge from the left ear, fever, rash and left axillary lymphadenopathy. Mendelian Susceptibility for mycobacterial disease ${ }^{7}$ tested negative. Clinical Exome was done at nine months of age and a heterozygous two base pair duplication in exon 8 of the NLRP12 gene chr19:g.54301596_54301597dupGA; Depth: 106x that results in a frame shift and premature truncation of the protein 6 amino acids downstream to codon 944 (p.Arg944SerfsTer6; ENST00000324134.6) was detected suggestive of autosomal dominant familial cold auto inflammatory syndrome-2 (OMIM\#611762) which is caused by heterozygous mutations in the NLRP12 gene (OMIM*609648); a variant of unknown significance, which requires parental testing for confirmation. However, this testing could not be done due to the limitations of COVID-19 pandemic in India.

The timeline of the disease is shown in Figure 1. 


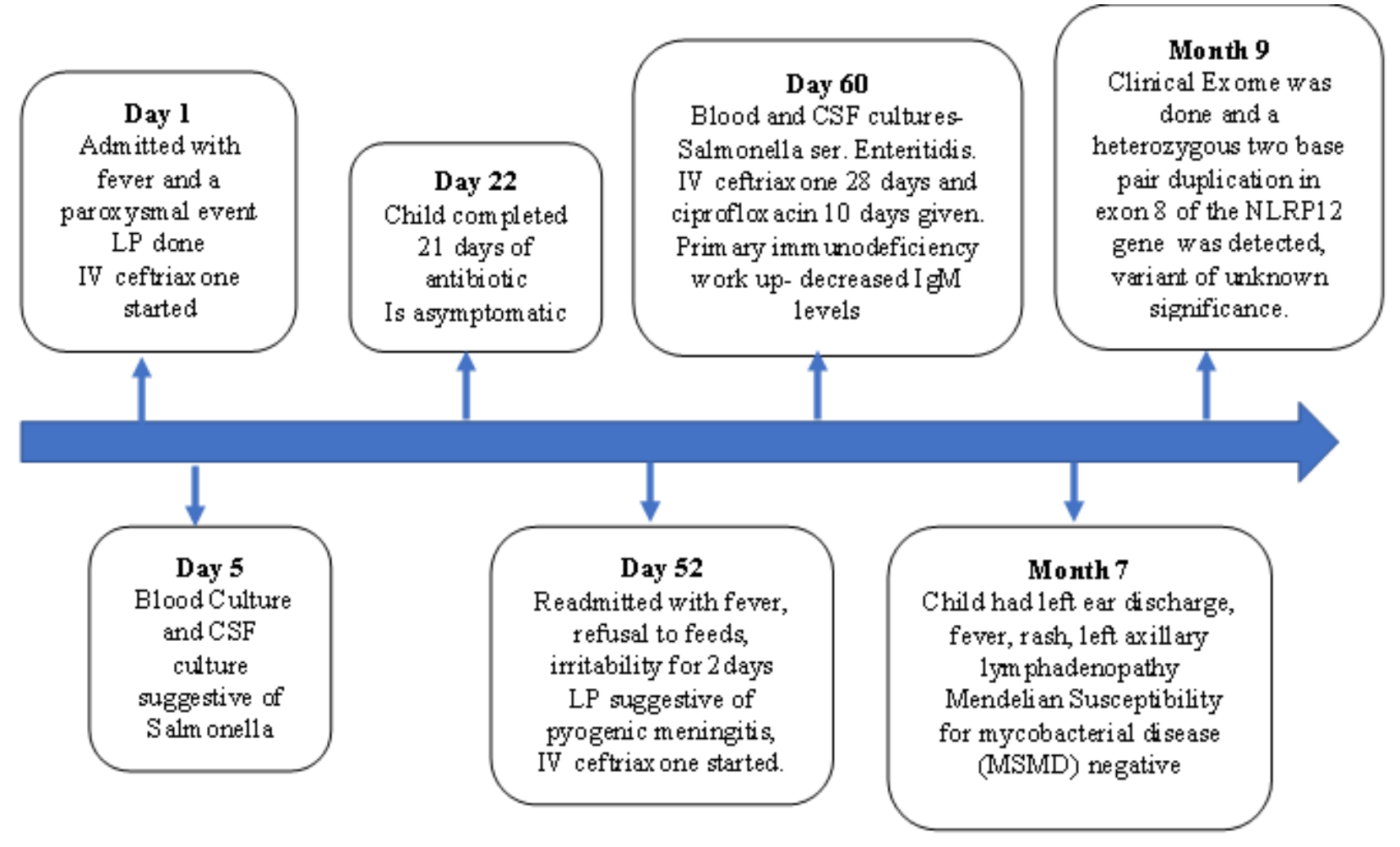

Figure 1: Timeline of the disease

\section{Discussion:}

Salmonella meningitis in infants has a wide spectrum of morbidity and complications, leading to a complicated hospital course and a high prevalence of permanent adverse outcomes. ${ }^{3}$ Thus early recognition of acute complications of Salmonella meningitis and a follow-up plan for early developmental assessment of the survivors is vital.

The genus Salmonella is a Gram-negative bacillus of the family Enterobacteriaceae. The most recent classification of Salmonella includes two species: Salmonella ser. Enterica and Salmonella ser. Bongori, S. Enteritidis belongs to serogroup D and corresponds to S. Enterica, subspecies enterica, serovar enteritidis. ${ }^{9,10}$ Non-typhoidal Salmonella (NTS) causes a selflimiting enterocolitis in immunocompetent individuals. ${ }^{11}$ Primary NTS bacteraemia can occur in the immunocompromised, and mortality is significantly higher in this group (up to $21 \%$ in some case series).$^{11}$ There is increased risk of Salmonella meningitis in infants less than 6 months of age. ${ }^{11}$

The drug of choice for treatment of Salmonella meningitis is a third-generation cephalosporin such as ceftriaxone which has intracellular penetration, and intracellular activity is dependent on the extracellular concentration achieved. ${ }^{12}$ Thus, for successful treatment, third-generation cephalosporin should be used in the dose that crosses the blood brain barrier, and continued for 4 weeks to ensure complete killing of the organism and to prevent relapse. ${ }^{13} \mathrm{~A}$ combination of 
ciprofloxacin and ceftriaxone or cefotaxime has been suggested too by Prince EH et $\mathrm{al}^{14}$ and the American Academy of Pediatrics. ${ }^{15}$

Complications during the acute phase of Salmonella meningitis include prolonged seizures (100\%), hydrocephalus (50\%), subdural collection (42\%), stroke (33\%), ventriculitis (25\%), empyema (13\%), brain abscess $(8 \%)$ and cranial nerve palsy $(8 \%){ }^{2}$ Long term follow-up is mandated to look for motor sequelae, epilepsy, language delay and cognitive delay. ${ }^{2}$

NLRP-12 is a key suppressor of innate immune signaling in salmonellosis. Any mutation in NLRP-12 gene may affect the Nuclear Factor Kappa B (NFKB) mediated destruction of Salmonella. Hence modulation of NLRP 12 expression and activation might help in prevention and treatment of Salmonella. ${ }^{16}$

NLRP12 Autoinflammatory disease (AID) is a rare autosomal dominant disorder caused by germline mutations in the NLRP12 gene and may have clinical manifestations of primary immune deficiencies (PID). ${ }^{17}$ Monarch-1 is involved in the inhibition of the inflammatory response. Mutations in the NLRP12 gene appear to reduce the ability of the monarch-1 protein to inhibit inflammation which contributes to caspase activation and hyperproduction of interleukin$1 \beta$. The role of NLRP12 in the pathogenesis of infectious diseases remains a subject of investigation. Treatment of NLRP12-AID is usually based on the use of NSAIDs or short-term course of corticosteroids, with only some patients requiring sophisticated targeted drugs. ${ }^{18}$

\section{Conclusion:}

Timely diagnosis of Salmonella meningitis, along with appropriate antibiotics for an adequate duration will reduce the mortality and morbidity. Early recognition of acute complications and a follow-up plan for early developmental assessment of survivors are vital. Immunodeficiency work up needs to be done in a case of recurrent Salmonella meningitis.

\section{Declarations}

Acknowledgments - We wish to acknowledge and thank the Dean of our institute, Dr Ramesh Bharmal, for giving permission to publish this article

Conflict of Interest statement - None

Funding source - None

Ethics statement and consent for publication - Not applicable

Author contributions - Preparation of first draft: AL, SS

Collection of Data: AL, SS, NN, NC

Interpretation of Data: SS, AL,

Literature Search: AL, NN, SS

Conceptualization: SS, AL, AD

Intellectual inputs for improvement of Manuscript: SS, NN, AL

Approval of Final Draft: SS, NN, AL, AD, NC, JS

\section{References}

1. Chen CJ, Wu FT, Hsiung CA et al. Risk factors for salmonella gastroenteritis in children less than five years of age in Taiwan. Pediatr Infect Dis J. 2012; 31(12):e239-43.

doi: 10.1097/INF.0b013e31826ff592. 
2. Wu HM, Huang WY, Lee ML et al. Clinical features, acute complications, and outcome of Salmonella meningitis in children under one year of age in Taiwan. BMC Infect Dis 2011; 11(1):30. doi: https://doi.org/10.1186/1471-2334-11-30 PMID: 21272341

3. Anne RP, Vaidya PC, Ray P et al. Salmonella typhimurium meningitis in an infant presenting with recurrent meningitis. Indian J Paediatrics 2018; 85(7):560-2.

doi: https://doi.org/10.1007/s12098-017-2562-3

4. Varaiya A, Saraswathi K, Tendolkar U et al. Salmonella enteritidis meningitis - A case report. Indian J Med Microbiol 2001; 19:151-2. PMID: 17664820.

5. Prober CG, Srinivas NS, Mathew R. Central Nervous System Infections. In: Kliegman, Stanton, St Geme, Schor, editors, Nelson Textbook of Pediatrics. 20th edition vol 2. Elsevier; 2016: 2936-43

6. Clinical and Laboratory Standard Institute. Performance Standards for Antimicrobial Susceptibility Testing; Twenty-Eighth Informational Supplement. CLSI document M100-S28 Wayne PA: Clinical and Laboratory Standard Institute; 2018.

7. Ozen M, Ceyhan M, Sanal O et al. Recurrent Salmonella bacteraemia in interleukin-12 receptor $\beta 1$ deficiency. $J$ trop paediatrics. 2006; 1; 52(4):296-8. doi:10.1093/tropej/fml001

8. Synnott MB, Morse DL, Hall SM. Neonatal meningitis in England and Wales: A review of routine national data. Arch Dis Child 1994; 71(2):F75-80. doi: 10.1136/fn.71.2.f75.

9. Wen SC, Best E, Nourse C. Non-typhoidal Salmonella infections in children: Review of literature and recommendations for management. J Paediatr Child Health 2017; 53(10):936-41 doi: https://doi.org/10.1111/jpc.13585

10. Brenner FW, Villar RG, Angulo FJ et al. Salmonella nomenclature. J Clin Microbiol. 2000; 38(7): 2465-7. doi: 10.1128/JCM.38.7.2465-2467.2000

11. Dhanoa A, Fatt QK. Non-typhoidal Salmonella bacteraemia: Epidemiology, clinical characteristics and its association with severe immunosuppression. Ann Clin Microbiol Antimicrob 2009; 8:15. doi: https://doi.org/10.1186/1476-0711-8-15

12. Fomda BA, Charoo BA, Bhat JA et al. Recurrent meningitis due to Salmonella enteritidis: a case report from Kashmir India. Indian J Med Microbiol. 2012; 30(4):474-6. doi: 10.4103/0255-0857.103776. PMID: 23183477

13. Monica F, Valentina C, Lisa M et al. Unusual meningitis caused by non-typhoid Salmonella in an Italian infant: a case report. Acta Biomed 2019; 90(2):333. doi: 10.23750/abm.v90i2.6866

14. Price EH, de Louvois J, Workman MR. Antibiotics for Salmonella meningitis in children. J Antimicrob Chemother. 2000; 46:653-5. doi.org/10.1093/jac/46.5.653

15. American Academy of Pediatrics. Committee on infectious diseases. Salmonella infections. In: Peter $\mathrm{G}$, editor. Report of the committee on infectious diseases.25 ${ }^{\text {th }}$ ed. Elk Grove Village, IL: American Academy of Pediatrics; 2000.p. 503

16. Zaki MH, Man SM, Vogel P et al. Salmonella exploits NLRP12-dependent innate immune signaling to suppress host defenses during infection. Proc Natl Acad Sci USA 2014; 111(1):385-90. doi: https://doi.org/10.1073/pnas.131764311110.

17. Subbarayan A, Colarusso G, Hughes SM et al. Clinical features that identify children with primary immunodeficiency diseases. Pediatrics 2011; 127(5):810-6.

doi: https://doi.org/10.1542/peds.2010-3680.

18. Vitale A, Rigante D, Maggio MC et al. Rare NLRP12 variants associated with the NLRP12autoinflammatory disorder phenotype: an Italian case series. Clin Exp Rheumatol. 2013; 31(3 Suppl 77):155-6. PMID: 24064030. 